\title{
Paleoparasitological report on Ascaris aDNA from an ancient East Asian sample
}

\author{
Chang Seok $\mathrm{Oh}^{1,2}$, Min Seo ${ }^{3}$, Nam Jin Lim ${ }^{4}$, Sang Jun Lee ${ }^{1,2}$, \\ Eun-Joo Lee ${ }^{5}$, Soong Deok Lee ${ }^{1}$, Dong Hoon Shin ${ }^{1,2} /+$
}

\begin{abstract}
IInstitute of Forensic Medicine 2Department of Anatomy, Seoul National University College of Medicine, 28 Yongon-dong, Chongno-Gu, Seoul 110-799, Korea ${ }^{3}$ Department of Parasitology, Dankook University College of Medicine, Chonan, Korea ${ }^{4}$ Gyeongi Institute of Cultural Properties, Suwon-si, Gyeonggi-do, Korea ${ }^{5}$ Department of Multiplex Contents, Andong National University, Andong, Korea
\end{abstract}

In this study, Ascaris DNA was extracted and sequenced from a medieval archaeological sample in Korea. While Ascaris eggs were confirmed to be of human origin by archaeological evidence, it was not possible to pinpoint the exact species due to close genetic relationships among them. Despite this shortcoming, this is the first Ascaris ancient DNA (aDNA) report from a medieval Asian country and thus will expand the scope of Ascaris aDNA research.

Key words: Ascaris - ancient DNA - cytochrome b - 18S rRNA

Successful recovery of ancient DNA (aDNA) from various parasite species has been reported by a number of investigators (Guhl et al. 1999, Sallares \& Gomzi 2001, Iñiguez et al. 2003, 2006, Aufderheide et al. 2004, Liu et al. 2007). In the case of ancient Ascaris spp, one of the most widespread parasitic infections in humans (Loreille \& Bouchet 2003), PCR-based analyses have been performed and reported by Loreille et al. (2001) and Leles et al. (2008). However, even though Ascaris spp have been identified by molecular studies of archaeological specimens, their genetic diagnosis has not been studied in greater detail so far (Anderson 2001, Peng et al. 2005, Leles et al. 2010). Moreover, since most aDNA studies on Ascaris have been limited in their geographical distribution to Europe and South America, it is desirable to secure Ascaris aDNA data from a much wider geographic and temporal range. In this regard, our report on the successful extraction and sequencing of Ascaris aDNA from Korean archaeological specimens, the first such report from an East Asian country, is a valuable addition to the existing pool of Ascaris aDNA.

A medieval tomb constructed during the Joseon Dynasty (1392-1910) was uncovered in Seocheon, Korea on August 19,2008. Similar to other medieval tombs in Korea, infiltration of contaminants from the outside was prevented by intact encapsulation of the lime-soil mixture barrier. The human remains were wrapped in very well preserved clothing. During removal of that clothing in our lab, textile specialists wore sterilised gowns, masks, gloves and head caps under contamination-minimised condition (Fig. 1A-C). Parasitological samples

Financial support: National Research Institute of Cultural Heritage, Korea (08D011Y-00110-2008)

+ Corresponding author: drdoogi@snu.ac.kr

Received 10 August 2009

Accepted 9 February 2010 spread upon the surface of hip bones were immediately collected during the removal of the textiles (Fig. 1D, E). This stringent condition helped prevent contamination by other sources such as animals, confirming that the parasite eggs found were truly of human origin.

The samples were rehydrated for microscopic examination according to previously reported methods (Callen \& Cameron 1960). Briefly, the samples were treated with $0.5 \%$ aqueous trisodium phosphate solution then filtered with multiple layers of gauze. After spontaneous sedimentation, the upper turbid layer was discarded and precipitates were dissolved in $20 \mathrm{~mL}$ rehydration solution. A volume of $20 \mu \mathrm{L}$ from each sample was observed by light microscopy (Olympus, Tokyo, Japan) and observations were repeated 10 times. The sizes of parasite eggs were measured and the number of parasite eggs per gram was estimated. We also performed microscopic and molecular studies on surface soil within a $1 \mathrm{~m}$ radius of the tomb, which were used as negative controls.

We (Labs A and B) extracted Ascaris aDNA from samples where Ascaris eggs were identified, using the method reported by Iñiguez et al. (2003). Primers for $A s$ caris cytochrome b (cyt b) and Ascaris 18S small subunit ribosomal RNA (18S rRNA) gene were made according to the method reported by Loreille et al. (2001). The laboratories used the same primer sets. aDNA was amplified by PCR in a $20-\mu \mathrm{L}$ reaction mixture containing $1 \mathrm{X}$ High Fidelity PCR buffer, $2 \mathrm{mM} \mathrm{MgSO}_{4}, 200 \mu \mathrm{M}$ dNTPs, two units of Platinum ${ }^{\circledR}$ Taq DNA Polymerase High Fidelity (Invitrogen, USA), $10 \mathrm{pmol}$ of each primer and $1 \mathrm{mg} / \mathrm{mL}$ BSA (New England Biolabs, USA). PCR was done as follows: pre-denaturation at $94^{\circ} \mathrm{C}$ for $10 \mathrm{~min}$; 50 cycles of denaturation at $94^{\circ} \mathrm{C}$ for $45 \mathrm{sec}$, annealing at $50^{\circ} \mathrm{C}$ for $45 \mathrm{sec}$ and extension at $72^{\circ} \mathrm{C}$ for $45 \mathrm{sec}$; and final extension at $72^{\circ} \mathrm{C}$ for $10 \mathrm{~min}$. Electrophoresis was done using a $2.5 \%$ agarose gel to identify amplified products.

Cloning of PCR products was performed using the pGEM-T Easy Vector system (Promega, USA) according to manufacturer's instructions. Sequencing of each clone was carried out with an ABI Prism 3100 auto- 

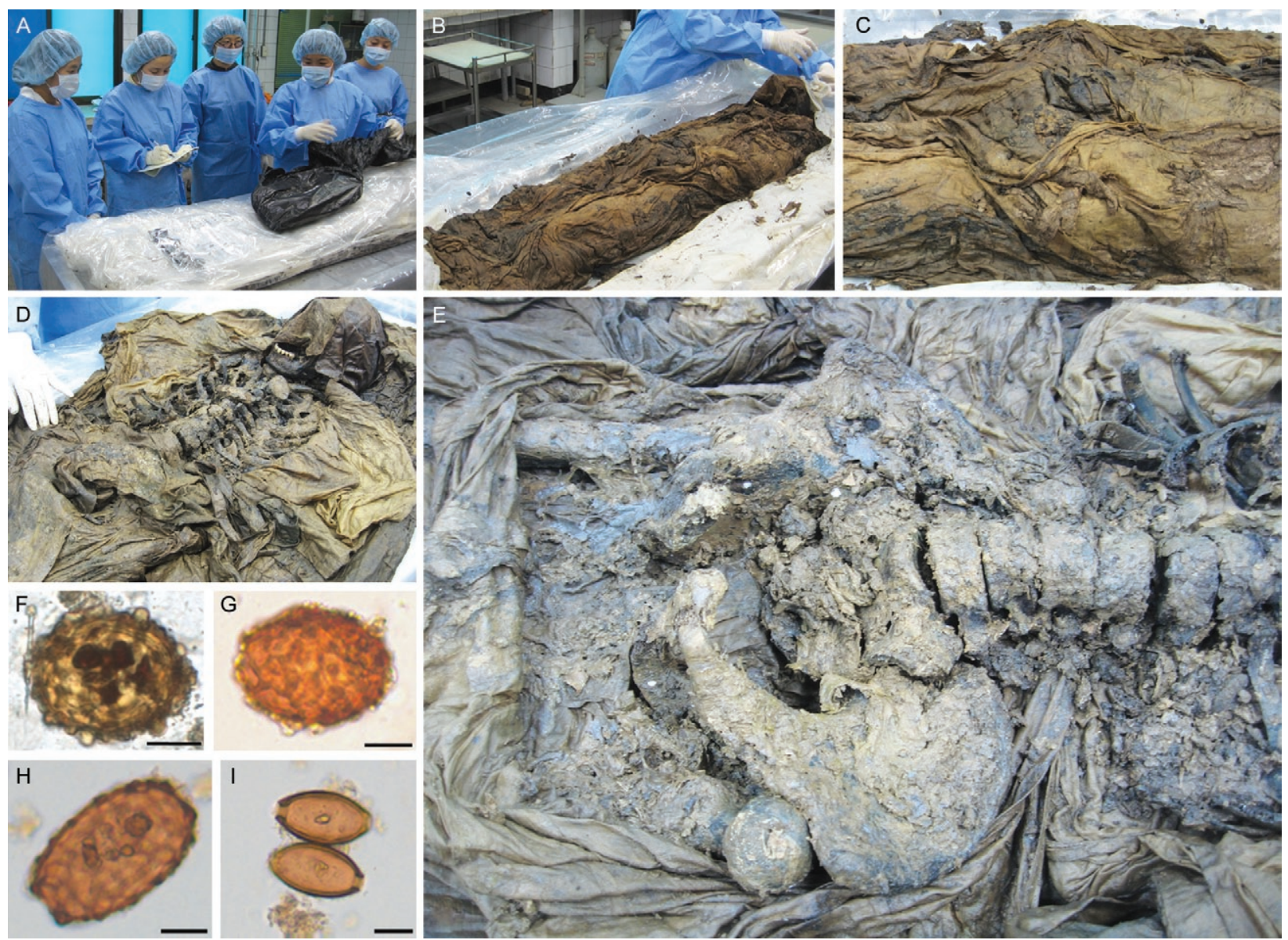

Fig. 1: A: as the dead body of this case was completely wrapped with very well preserved clothe we moved it from archaeological field to our lab without any derangements of the clothes. The textile was removed in the lab; B: the dead body was well wrapped by clothes; C: magnified image of pelvic region which was perfectly wrapped by clothes. When the human remains within the clothes were finally exposed to us we collected the parasitological sample spread upon the surface of hip bones; D: before the textile draped upon pelvic bones; E: after all the textiles were removed. The sample could be eventually exposed to us for the first time after burial. We collected the precipitates the sample spread upon the both sides of hip bones; F-I: parasite eggs found in the sample; F, G: fertile Ascaris lumbricoides eggs; H: infertile A. lumbricoides egg; I: Trichuris trichiura eggs. Bars $=20 \mu \mathrm{m}$.

matic sequencer (Applied Biosystems, USA) and the ABI Prism BigDye Terminator Cycle Sequencing Ready Reaction Kit (Applied Biosystems, USA). We repeated cloning and sequencing 2-5 times for each amplified product. Sequences were analysed using the BioEdit sequence alignment editor version 7.0.9.0 (http://mbio. ncsu.edu/BioEdit/bioedit.html). In Lab B, PCR products were directly sequenced and compared with the consensus sequence obtained in Lab A. Sequences obtained from the laboratories were also compared with public databases using BLAST searches (http://www.ncbi.nlm. nih.gov/BLAST). aDNA analysis was done according to criteria of authentication (Hofreiter et al. 2001). We did not perform any DNA work with modern Ascaris spp in our lab before the current study. We also set up our aDNA lab facilities in accordance with the suggestions of Hofreiter et al. (2001) (Supplementary data).

We observed fertile or infertile Ascaris and Trichuris trichiura eggs in the Seocheon sample under the light microscope (Fig. 1F-I). The average sizes of Ascaris eggs were $65 \pm 1.2 \mu \mathrm{m}$ (length) and $51 \pm 3.4 \mu \mathrm{m}$ (width). The estimated number of eggs was 6714.3 per gram. In PCRbased aDNA analyses, fragments of Ascaris 18S rRNA and $c y t \mathrm{~b}$ mitochondrial genes were successfully amplified while negative controls (surface soil and extraction controls) did not show any amplified bands (Fig. 2).

In Lab A, cloning and sequencing was performed on the amplified fragments of 18S rRNA (176 bp) and cyt B (98 bp) genes. Among 113 clones of 18S rRNA gene (Asc6 and Asc7, Asc8 and Asc9, Asc10 and Asc11), 63 sequences were successfully obtained. For the $c y t \mathrm{~b}$ gene (Asc1 and Asc2), 24 sequences were obtained from 25 clones. We found that eight clone sequences (SC89-B1, SC89-B2, SC89-C6, SC89-C7, SC1011-A8, SC1011-A10, SC1011-B10 and SC12-A13) had single nucleotide substitutions and three nucleotide substitutions were found in clone SC12-B3. When the consensus sequences of $18 \mathrm{~S}$ rRNA and cyt $\mathrm{b}$ genes obtained in Lab A were compared with direct sequencing results in $\mathrm{Lab} \mathrm{B}$, the results were identical (Fig. 3). Next, the sequences were compared 

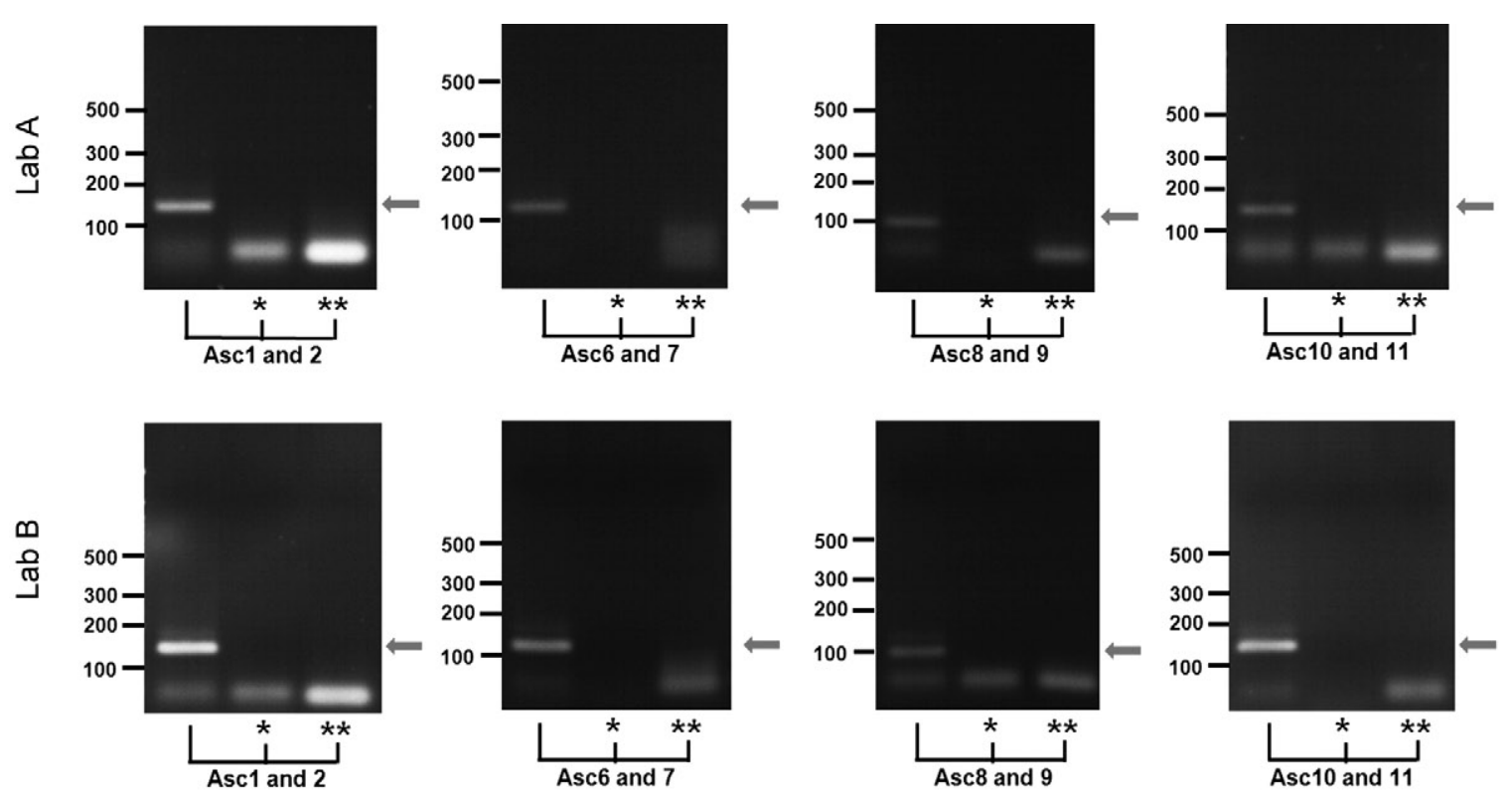

Fig. 2: electrophoresis results of PCR products (18S rRNA and cyt $\mathrm{b}$ mitochondrial genes). Red arrows indicate the specific bands. Scales (100, 200, 300 and 500) in left is for bp. Laboratories obtained specific bands in all the PCR products. Asterisk means surface soil. Double asterisk means extraction control. Both did not show any specific bands.

18S small subunit robosomal RNA gene
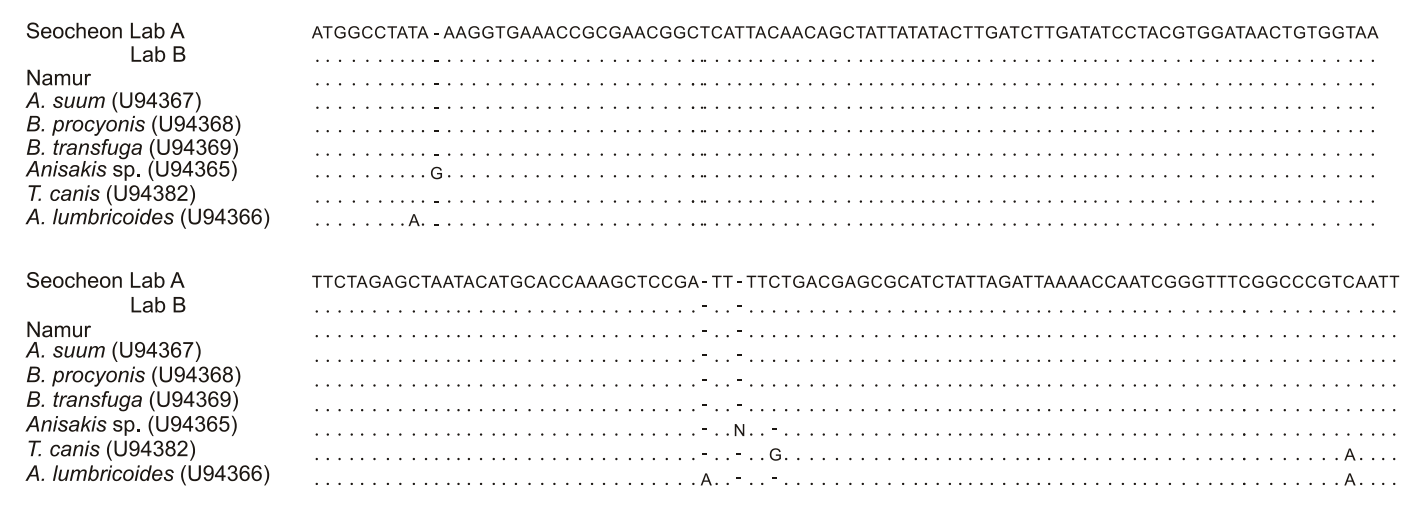

Mitochondrial cytochrome b (cyt b) gene

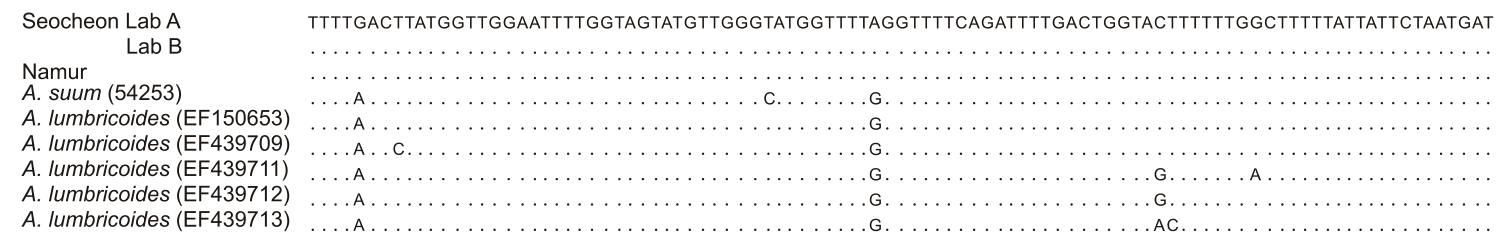

Fig. 3: comparison of sequences for Ascaris 18S rRNA and cyt b mitochondrial genes obtained in Lab A (consensus sequence) and B (direct sequencing result) and those of Ascaris suum or Ascaris lumbricoides identified in GenBank.

to those in GenBank. Our 18S rRNA gene sequence was $100 \%$ identical to that of Namur (Loreille et al. 2001), Ascaris suum (U94367), Baylisascaris transfuga (U94369) and Baylisascaris procyonis (U94368). They also showed similarities to 18S rRNA genes of Anisakis sp. (98\%, U94365), Toxocara canis (97\%, U94382) and Ascaris lumbricoides (97\%, U94366). For the As- caris cyt b sequence, our result showed 100\% identity to Namur (Loreille et al. 2001); 97\% to Ascaris lumbricoides gene (EF150653, Brazil; EF439710, Lubeck, Germany; EF439714 to EF439718, Walraversijde, Belgium; EF439722, Minas Gerais, Brazil); 96\% to A. suum (X54253) and A. lumbricoides (EF439709, Lubeck, Germany; EF439712, Walraversijde, Belgium; EF439719, 
Walraversijde, Belgium; EF439720 and EF439721, Minas Gerais, Brazil; EF439723, Piauí, Brazil; EF439724, San Pedro de Atacama, Chile). However, some A. lumbricoides sequences (EF439711, Lubeck, Germany; EF439713, Walraversijde, Belgium) showed only $95 \%$ identity to our cyt $\mathrm{b}$ sequence. Considering that most previously reported Ascaris sequences are from European or South American countries, the results from this study improve the range of information collected on $\mathrm{As}$ caris aDNA by adding data from East Asia, thereby expanding the geographical scope.

However, even though our Ascaris eggs are likely of human origin, the Ascaris 18S rRNA gene sequence was more similar to $A$. suum than to A. lumbricoides. In addition, some previously reported mitochondrial cyt $\mathrm{b}$ gene sequences of $A$. lumbricoides in GenBank showed less similarity to our Ascaris sequence than $\operatorname{did}$ A. suum. Therefore, the aDNA analysis reported here falls short of confirming the Ascaris aDNA as A. lumbricoides. Many currently available nuclear or mitochondrial targets are not satisfactory for differentiating A. lumbricoides from A. suum (Anderson 2001, Peng et al. 2005, Leles et al. 2010), which stems from the close relationship between the two species (Barry \& O’ Rourke 1967, Crompton 1989, Zhu et al. 1999, Leles et al. 2010). This is again evident in our study because the differentiation between these two species was not achieved after genetic analysis.

\section{REFERENCES}

Anderson TJC 2001. The dangers of using single locus markers in parasite epidemiology: Ascaris as a case study. Trends Parasitol 17: 183-188.

Aufderheide AC, Salo W, Madden M, Streitz J, Buikstra J, Guhl F, Arriaza B, Renier C, Wittmers Jr LE, Fornaciari G, Allison M 2004. A 9000-year record of Chagas' disease. Proc Natl Acad Sci USA 101: 2034-2039.

Barry JM, O’ Rourke FJ 1967. Ascariasis in pig and in man. Sci Proc $R$ Dublin Soc Ser A 3: 39-55.

Callen EO, Cameron TWM 1960. A prehistoric diet as revealed in coprolites. New Sci 8: 35-40.
Crompton DWT 1989. Biology of Ascaris lumbricoides. In DWT Crompton, MC Nesheim, ZS Pawlowski (eds.), Ascariasis and its prevention and control, Taylor \& Francis, London, p. 10-44.

Guhl F, Jaramillo C, Vallejo GA, Yockteng R, Cárdenas-Arroyo F, Fornaciari G, Arriaza B, Aufderheide AC 1999. Isolation of Trypanosoma cruzi DNA in 4000-year-old mummified human tissue from Northern Chile. Am J Phys Anthropol 108: 401-407.

Hofreiter M, Serre D, Poinar HN, Kuch M, Pääbo S 2001. Ancient DNA. Nat Rev Genet 2: 353-359.

Iñiguez AM, Reinhard K, Carvalho Gonçalves ML, Ferreira LF, Araújo A, Paulo Vicente AC 2006. SL1 RNA gene recovery from Enterobius vermicularis ancient DNA in pre-Columbian human coprolites. Int J Parasitol 36: 1419-1425.

Iñiguez AM, Reinhard KJ, Araújo A, Ferreira LF, Vicente ACP 2003. Enterobius vermicularis: ancient DNA from North and South American human coprolites. Mem Inst Oswaldo Cruz 98: 67-69.

Leles D, Araújo A, Ferreira LF, Vicente ACP, Iñiguez AM 2008. Molecular paleoparasitological diagnosis of Ascaris sp. from coprolites: new scenery of ascariasis in pre-Columbian South America times. Mem Inst Oswaldo Cruz 103: 106-108.

Leles D, Araújo A, Vicente AC, Iñiguez AM 2010. ITS1 intra-individual variability of Ascaris isolates from Brazil. Parasitol Int 59: 93-96.

Liu W-Q, Liu J, Zhang J-H, Long X-C, Lei J-H, Li Y-L 2007. Comparison of ancient and modern Clonorchis sinensis based on ITS1 and ITS2 sequences. Acta Tropica 101: 91-94.

Loreille O, Bouchet $\mathrm{F} 2003$. Evolution of ascariasis in humans and pigs: a multi-disciplinary approach. Mem Inst Oswaldo Cruz 98: 39-46.

Loreille O, Roumat E, Verneau O, Bouchet F, Hänni C 2001. Ancient DNA from Ascaris: extraction amplification and sequences from eggs collected in coprolites. Int J Parasitol 31: 1101-1106.

Peng W, Yuan K, Hu M, Zhou X, Gasser RB 2005. Mutation scanningcoupled analysis of haplotypic variability in mitochondrial DNA regions reveals low gene flow between human and porcine Ascaris in endemic regions of China. Electrophoresis 26: 4317-4326.

Sallares R, Gomzi S 2001. Biomolecular archaeology of malaria. Anc Biomol 3: 195-213.

Zhu X, Chilton NB, Jacobs E, Boes J, Gasser RB 1999. Characterization of Ascaris from human and pig hosts by nuclear ribosomal DNA sequences. Int J Parasitol 29: 469-478. 


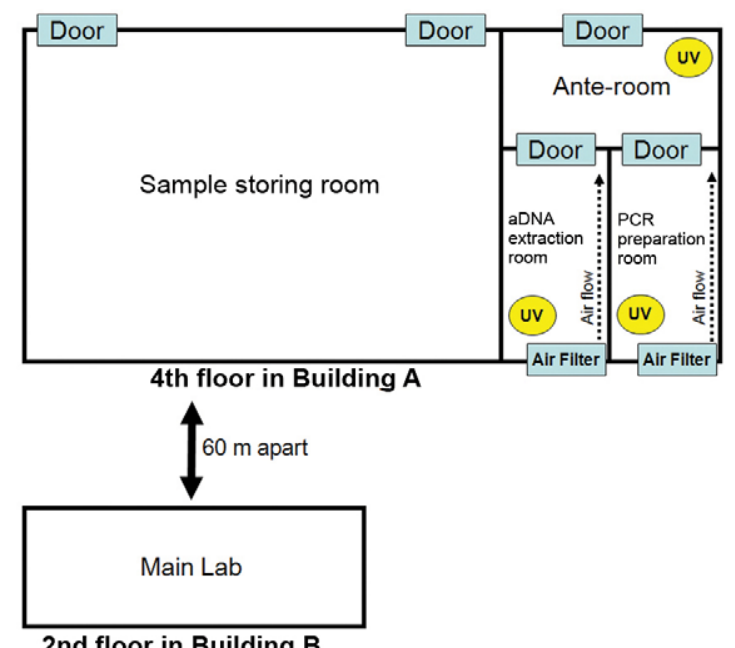

Both ancient DNA (aDNA) labs participated in this work have facilities exclusively dedicated to aDNA work. This is the example of Lab A. The distance between aDNA extraction or PCR preparation rooms of Building A and main PCR lab in Building B is about $60 \mathrm{~m}$. There is not any lab performing PCR amplification of modern DNA on 4th floor in Building A. The rooms for aDNA extraction or PCR preparation were separated from our main lab where we did PCR works. The rooms were equipped with night UV irradiation, isolated ventilation, or laminated flow hood. The researchers in Lab A followed instructions in Criteria of Authenticity (Hofreiter et al. 2001). None could enter into aDNA extraction or PCR preparation rooms without permission. 